Article

\title{
Theory of Mind, Executive Functions, and Syntax in Bilingual Children with Autism Spectrum Disorder
}

\author{
Maria Andreou ${ }^{1, *} \mathbb{0}$, Ianthi Maria Tsimpli ${ }^{2}$, Stephanie Durrleman ${ }^{3}$ and Eleni Peristeri ${ }^{4}$ \\ 1 Department of English, University of Cologne, Luxemburger Str. 299, 50939 Cologne, Germany \\ 2 Department of Theoretical and Applied Linguistics, University of Cambridge, English Faculty Building, \\ 9 West Road, Cambridge CB3 9DP, UK; imt20@cam.ac.uk \\ 3 Department of Linguistics, University of Geneva, 2 rue de Candolle, 1205 Geneva, Switzerland; \\ stephanie.durrleman@unige.ch \\ 4 Department of Neurology, University of Thessaly, 41110 Larisa, Greece; eperiste@uth.gr \\ * Correspondence: mandreou@uni-koeln.de
}

Received: 23 September 2020; Accepted: 18 November 2020; Published: 25 November 2020

\begin{abstract}
Impairments in Theory of Mind (ToM) are a core feature of Autism Spectrum Disorder (ASD). ToM may be enhanced by various factors, including bilingualism, executive functions (EF), and complex syntax. This work investigates the language-cognition interface in ASD by exploring whether ToM can be enhanced by bilingualism, whether such ToM boosts would be due to EF or syntax, and whether routes to mentalizing would differ between bilinguals and monolinguals on the spectrum. Twenty-seven monolingual Greek-speaking and twenty-nine bilingual Albanian-Greek children with ASD were tested on ToM reasoning in verbal and low-verbal ToM tasks, an executive function 2-back task, and a sentence repetition task. Results revealed that bilingual children with ASD performed better than monolinguals with ASD in the low-verbal ToM and the 2-back tasks. In the sentence repetition task, bilinguals scored higher than monolinguals in complex sentences, and specifically in adverbials and relatives. Regarding the relations between ToM, EF, and sentence repetition, the monolingual group's performance in the verbal ToM tasks was associated with complement syntax, whereas, for the bilingual children with ASD, performance in both verbal and low-verbal ToM tasks was associated with EF and adverbial clause repetition. The overall pattern of results suggests that mentalizing may follow distinct pathways across the two groups.
\end{abstract}

Keywords: Autism Spectrum Disorder; bilingualism; theory of mind; syntax; executive functions

\section{Introduction}

Mentalizing skills, also known as Theory of Mind (ToM), refer to one's ability to attribute cognitive states (beliefs, intentions) and emotions to both oneself and others and to predict ensuing behaviors (i.e., belief attribution to oneself and others, Nguyen and Astington 2014), and it is a crucial skill for successful social interactions (Mazza et al. 2017; Derksen et al. 2018). Core weaknesses in ToM, thus, explain the widespread difficulty experienced by individuals with Autism Spectrum Disorders (ASD) in social situations (e.g., Baron-Cohen 1991; Baron-Cohen et al. 1985; Schuh and Eigsti 2012). Executive function deficits have also been recurrently reported in individuals with ASD (Adesope et al. 2010, Carlson and Meltzoff 2008), and these deficits exacerbate their ToM impairments (e.g., Ozonoff et al. 1991; Solomon et al. 2009). Humans' beliefs, thoughts, and intentions often diverge, and successful mentalizing requires reconciling a conflict between one's own beliefs and another's (Russell et al. 1999), or updating one's model of the world (Asakura and Inui 2016). In addition to executive function (EF) impairments, language difficulties have also been found to influence ToM in ASD. More specifically, research has shown that individuals on the spectrum with 
a grasp of sentential complements, e.g., "John thinks/says that the world is flat," succeed better at belief-reasoning relative to individuals with ASD displaying a lower performance in embedded clause understanding (Durrleman et al. 2019, 2016; Durrleman and Franck 2015; Li and Leung 2020). This is to be expected in light of de Villiers' $(2000,2005,2007)$ work, which has shown that the ability to embed a sentence into another one is an essential ingredient in the development of ToM in typically-developing (TD) children.

TD bilingual children show an interesting asymmetry between language and cognitive control skills since they may present lower vocabulary (Bedore et al. 2012) and syntactic skills (Andreou and Tsimpli 2020), while they tend to show advantages in EF (Bialystok 2015; Carlson and Meltzoff 2008). However, we should note that bilingual children do not always display lower language skills than their monolingual peers. For instance, vocabulary is not lower in bilinguals when the sum of comprehension and production vocabulary items of the two languages is considered (Hoff et al. 2012; Pearson et al. 1993). These studies found no evidence of differences between bilinguals' and monolinguals' vocabulary sizes, further suggesting that the claim that bilingual children know fewer words than monolingual children do is a misconception. In addition, bilingualism does not appear to aggravate pre-existing language impairments. If a child has difficulty with learning one language, they will have difficulty learning another, but it will not be harder (Peña et al. 2018). In their study, Peña and colleagues reveal that bilingual children with primary language impairment are even advantaged relative to monolingual children with language impairment on measures of morphosyntax and semantics.

Regarding autism, bilingualism has been shown to have no detrimental effect on the children's language skills either, including expressive and receptive vocabulary, syntactic, morphological, and pragmatic skills (see Hambly and Fombonne 2012; Gonzalez-Barrero and Nadig 2018; Meir and Novogrodsky 2020; Ohashi et al. 2012; Petersen et al. 2012; Valicenti-McDermott et al. 2013). These studies provide converging evidence that bilingualism does not exacerbate the language difficulties of children with autism, and, thus, this common misconception is not backed by evidence-based research. Besides language, there is evidence suggesting a bilingual advantage in set-shifting skills for children with autism (Gonzalez-Barrero and Nadig 2019). These findings raise the question whether bilingual children with ASD can compensate for autism-related ToM deficits because of an EF and/or a social cognition advantage, or whether low syntactic skills remain persistent barriers to succeeding at ToM tasks, including low-verbal tasks. The aim of the current study is to investigate whether bilingualism may provide benefits for ToM in children with ASD, and to explore whether bilingual children with ASD follow different routes for mentalizing than monolingual children with ASD regarding their reliance on EF and/or language abilities. We are also concerned with elucidating whether a low-verbal ToM task would be less dependent on language skills than verbal ToM tasks across monolingual and bilingual children with ASD.

\subsection{The Role of Language in ToM in ASD}

Recent investigations of the interplay between ToM and grammar suggest that grammatical knowledge of complementation is a key sub-step in ToM development in TD children (Astington and Jenkins 1999; de Villiers 1998; de Villiers and de Villiers 2000). In fact, embedded clause understanding has been claimed to be isomorphic to embedding others' perspectives into one's own or vice-versa, suggesting common cognitive substrates for belief representation across the language and the ToM domain (Cheung et al. 2009; Tager-Flusberg 2013), as opposed to the possibility that meta-representations consist solely in representing other people's mental states in modality-specific representations.

Recent years have seen an increased interest in how ASD children's false belief attribution skills interact with language. In false belief tasks, grasping the content of characters' beliefs is based on analyzing what those characters have previously experienced or not. For example, in the classic Sally-Ann task, participants would need to reason that Sally saw that the ball was put in the basket. However, she did not witness, in contrast to them, that it was moved to the box. Thus, the ability to understand the world from another person's point of view requires the perceiver to embed other 
individuals' mental representations into her/his own hierarchically, yielding meta-representations. Similarly, sentence embedding allows constructing complex relations between the self and others because it enables the individual to refer to mental representations of events that are independent from the reality of physical events. Specifically, complement clauses occurring after cognition verbs (e.g., believe, think, guess, forget, predict) establish links between the epistemic modality expressed in the matrix clause and the situation expressed in the complement clause. For example, in the complex clause, 'Sally thinks that the ball is in the basket,' a relation is established between the propositional attitude conveyed by the epistemic verb 'thinks' and the argument expressed in the complement clause and supports a belief, an inference, a desire, or a supposition. Importantly, the truth (or falsity) of epistemic complement clauses cannot be presupposed by the propositional content of the main clause, such that the perceiver may recover the speaker's belief only by taking her/his perspective and imagining what he or she could have said from that perspective. This potentially involves consideration of the speaker's epistemic state, which, in turn, presupposes ToM skills.

There are multiple lines of evidence that point to a deficit in representing mental states in autism. Children diagnosed with ASD have shown failure in ToM tasks that tap into other-referential cognition (Bodner et al. 2015; Frith 2003; Frith and Happé 1999; Williams 2010), which may underpin social functioning and communication deficits in the disorder. Researchers link poor meta-representational ability in ASD, and, consequently, failure at false belief attribution tasks to poor embedded clause understanding (Durrleman et al. 2019, 2016; Durrleman and Franck 2015; Li and Leung 2020). Similarly, Peristeri et al. (2017) found that the use of ToM terms, i.e., units of information that involved the story characters' thoughts and feelings, in narrative production was positively associated with ASD children's knowledge of sentence embedding. This was reflected in the high frequency of complement clauses in the oral narrations of these children. Importantly, Durrleman et al. (2016) found that ASD children's false belief reasoning assessed by a nonverbal ToM task was related to complement clause understanding. This suggests that meta-representational cognitive capacities in autism are specifically related to the maturation of the syntax of complementation and, moreover, do not appear to be the mere result of testing ToM verbally. However, the vast majority of false belief tasks across studies do not only rely on parsing verbal information such as advanced mental state vocabulary (Baron-Cohen et al. 2001), comprehension of a variety of complex structures including interrogatives and past tense (Astington et al. 2002; Happé 1994; Devine and Hughes 2013), but they moreover impose high cognitive demands such as on working memory (Bull et al. 2008). These methodological choices may explain ASD children's struggle with ToM tasks, independently of their ToM abilities.

\subsection{The Role of EF in ToM in ASD}

EF is an umbrella term that encompasses a set of skills related to an individual's cognitive control. Executive dysfunction is commonly reported as a feature of ASD. Findings indicate that response inhibition, working memory, and mental flexibility—as assessed through parent-rating EF measures, spatial reversal, color-word interference, and Tower tests-are impaired in ASD (Gardiner and Iarocci 2018; Pennington et al. 1997; Semrud-Clikeman et al. 2010; see O'Hearn et al. 2008; Russell 1997 for a review). Impairment in EF has been proposed to explain social-communication deficits in ASD (Leung et al. 2016; Torske et al. 2018). Specifically, inhibition (assessed through the Day-Night and the NEPSY Knock-Tap tests) and planning (assessed through the NEPSY Tower test) have been related to performance on first-order false belief tasks in ASD (Joseph and Tager-Flusberg 2004). $\mathrm{EF}$ tested though card sorting, the digit span, and color-word interference tasks have also been found to be highly associated with ToM in adolescents (Jones et al. 2018) as well as in school-aged children with ASD (Kouklari et al. 2018). In the Peristeri et al.'s (2020) recent study, bilingual children with ASD outperformed their monolingual peers with ASD in a visual attention-shifting EF task in which the bilingual group exhibited a less detailed/local-focused processing style relative to monolinguals. The discerning differences between the two groups in the EF task were shown to affect children's use 
of affective ToM in terms of oral narration since more mental state terms were encountered only in bilingual children with ASD who exhibited more efficient attention-shifting capacity.

Though the findings regarding the links between ToM reasoning and EF appear to be consistent across studies with individuals with ASD, the source(s) of the ToM-EF association is little understood. It has been proposed that EF are more strongly related to one's mentalizing skills in ToM tasks that have high cognitive load and contextual demands (White et al. 2013). Such an account suggests a potentially common cognitive substrate between complex ToM reasoning and EF. Buac and Kaushanskaya (2020) have recently detected a link between ToM and EF in bilingual children that was critically mediated by the children's language exposure backgrounds. Others suggest that EF are associated with ToM skills through metacognition. The latter involves skills such as working memory, activity initiation, planning/organization, self-monitoring, and cognitive flexibility that allows one to disengage from a certain state-of-mind so as to adapt to a new situation. Thus, it is possible that individuals with ASD can be more efficient at reflecting on another individual's mental states due to their ability to display more flexible and adaptive metacognitive skills. Leung et al. (2016) found that stronger metacognitive abilities in working memory, planning, organization, and monitoring in a group of children with ASD were associated with fewer social deficits in this population, which suggests that there may be a unique link between metacognitive processes and social functioning in children with ASD. Another study compared metacognition to behavior regulation and found that metacognitive processes were the most important factor in accounting for social function in children with ASD (Torske et al. 2018). Despite the fact that both EF and mentalizing skills may have improved in bilinguals on the spectrum compared to their monolingual peers as indicated by a preliminary study that utilized a two-back test and first-order false belief attribution tasks (Baldimtsi et al. 2020), there is no research exploring the relationship between these domains in monolingual children compared to bilingual children with ASD. To address this lacuna in the literature, we examine the contribution of EF to the verbal and low-verbal ToM performance of both groups of children.

\subsection{The Current Study}

This work seeks to investigate bilingualism effects in the verbal and low-verbal ToM performance of children with ASD. For this purpose, we have tested 27 monolingual and 29 bilingual children with ASD, and we used analyses of behavioral accuracy responses in offline verbal first-order ToM tasks, and reaction times (RT) and accuracy in an online low-verbal first-order ToM task, specifically teasing out extra cognitive and/or language demands characteristic of most ToM studies on ASD. The study also aimed to better understand the distinctions and similarities in manifestations of executive and language deficits across the two experimental groups. Children were administered a two-back task that tapped into their working memory and updating skills. This task has been claimed to implicate a broad range of EF (Friedman and Miyake 2004; Hasher et al. 2002), since it requires temporary storage of each digit in working memory, monitoring information, and replacing the irrelevant memory representations with those relevant to the task (Morris and Jones 1990). The choice of the previously mentioned task was judged to be appropriate for the purposes of the current study, since it allowed us to test the link between the function of updating and ToM due to the latter being claimed to require updating of one's model of the world. Besides the EF task, the children were administered two language ability tasks that tapped into their expressive vocabulary and sentence repetition skills. The combination of these tasks allowed us to examine the extent to which group performance differences in the verbal and low-verbal ToM task would stem from their updating and/or language abilities.

Regarding sentence repetition, the test that has been used in the current study has been developed within the COST Action IS0804 in an attempt to establish whether sentence repetition can contribute to disentangling bilingual children with typical development from children with language impairment (Fleckstein et al. 2018; Meir et al. 2016). The use of sentence repetition tasks across the two populations is important given the similarities in the linguistic profile that several studies have reported (see Paradis 2010 for an overview). For example, studies with L2 children with typical 
language development and with fewer than three years of exposure have shown that they perform below their TD monolingual peers and exhibit a profile similar to that of monolingual children with language impairment (Paradis 2010).

The sentence repetition task that has been employed in the current study has subordinate sentences of various types, including complement, adverbial, and relative clauses (see the method). Our aim was to investigate group differences in sentence repetition, and, more importantly, to identify the types of subordinate clauses that would be linked to the ToM and/or EF performance of each group. Previous work has identified strong associations between EF and the types of subordination in typical bilingual development. More particularly, the Andreou and Tsimpli's (2020) study focused on syntactic complexity in language production as a measure of language ability in TD bilingual children. Their large-scale study consisted of 259 bilingual and monolingual TD children who were tested in the production of complex sentences via a narration task. Andreou and Tsimpli's (2020) results indicate that complement clauses belong to a core syntax, whereas adverbials seem to operate at the syntax-discourse interface where cohesion is relevant and the coherence of the narrative is established. Interestingly, the same study showed a correlation between adverbial clauses and bilingual children's cognitive skills, namely updating. The authors claimed that the use of adverbial clauses is transferable between the languages of the bilingual child, whereas complement clauses rather depend on language-specific properties. However, the Andreou and Tsimpli's (2020) study did not test the relation between EF, syntax, and ToM in the bilingual children.

Shifting to children with ASD, to the best of our knowledge, there has been only one study (Meir and Novogrodsky 2019) that has investigated the combined effects of bilingualism and ASD on the sentence repetition skills of school-aged children. According to the study's findings, bilingual children with ASD being at risk of language impairment did not perform worse than their monolingual peers with ASD in sentence repetition, which suggests that bilingualism did not impede their syntactic ability. Nevertheless, it remains to be determined how bilinguals with ASD manage with the various types of subordinate clauses in sentence repetition.

In the Peristeri et al.'s (2017) study, two groups of monolingual children with ASD, one with high-language ability and the other with low-language ability, dissociated across types of subordinate clauses in narrative production. Specifically, the frequency of use of complement and modifier (i.e., adverbial and relative) clauses showed divergent patterns in their relationship with the children's language ability level. The high-language ability group with ASD used considerably more complement clauses than the low-language ability group, even though the two groups were not found to significantly differ in the rates of the modifier (i.e., adverbial and relative) clauses. This contrast has led to the hypothesis that complement and modifier clauses may serve different linguistic functions. The use of complement clauses in discourse is mainly motivated by the syntactic licensing requirements of the verb in the higher clause (Haegeman 2006; Radford 1997), while modifier clauses are adjuncts that mainly align with pragmatic considerations, such as establishing coherent causal or temporal relations between propositions (Thompson et al. 1985; Vieu et al. 2005). The Peristeri et al.'s (2017) study showed that low-language ability in the cohort of children with ASD had a detrimental effect on the use of syntactically-motivated subordinate structures, i.e., complements, while high-language ability seemed to enhance the use of modifier clauses that fulfilled pragmatic felicity purposes in the children's narrations. Though these findings provide insight into how different aspects of subordinate clauses map into ASD children's narrative performance, there is no evidence on how bilingual language experience may influence the ability to repeat subordinate clauses, and how different subtypes of subordinates (e.g., adverbials, complements, relatives) may mediate monolingual and bilingual ASD children's ToM performance.

Thus, our current research questions and hypotheses regarding children with ASD are as follows:

Question 1. What is the effect of bilingualism on their mastery of ToM (measured verbally and low-verbally), EF, and subordination (measured via sentence repetition)? 
Hypothesis 1. Based on previous research (Goetz 2003) that bilingualism improves TD children's ToM skills, we hypothesized that bilingual children with ASD would perform better than their monolingual peers on ToM. Nevertheless, such a benefit was expected to be mostly evident on the low-verbal ToM task, since we hypothesized that bilingual ASD children's performance in the verbal ToM tasks would be confounded by the tasks' language demands. Furthermore, based on previous studies showing that bilingualism boosts EF in both TD children (Andreou and Tsimpli 2020; Andreou 2015; Bialystok 2015; Carlson and Meltzoff 2008) and children with ASD (Baldimtsi et al. 2020; Peristeri et al. 2020), we expected that bilingual children with ASD would exhibit superior performance to the monolingual group with ASD in the 2-back working memory task. Finally, following Meir and Novogrodsky's (2019) findings, we expected bilingual children with ASD to be similar to their monolingual peers on overall sentence repetition scores. Yet, we expected the bilingual group to score higher than monolinguals in modifier clauses and lower than monolinguals in complement clauses. We anticipated this asymmetry due to the possibility of bilingualism negatively affecting the repetition of syntax-conditioned complements and positively affecting the repetition of pragmatics-conditioned modifier clauses (see Andreou and Tsimpli 2020; Peristeri et al. 2017).

Question 2. How are their EF and sentence repetition skills linked to performance in verbal and low-verbal ToM tasks?

Hypothesis 2. We hypothesized that both monolingual and bilingual ASD children's performance in a low-verbal ToM task would be modulated by their EF skills, while performance in the verbal ToM task would be mostly affected by their language ability, as reflected by their performance in the sentence repetition task.

\section{Methods}

\subsection{Participants}

The study included 27 monolingual and 29 bilingual children with ASD (Mage $=10,4$ years, age range: from 7, 2 years to 15, 6 years, for ASDmono, Mage $=10,4$ years, age range: from 8, 3 years to 14,5 years, for ASDbi). All the monolingual and bilingual children with ASD who participated in the current study had full scale IQ within the normal range. Thus, they were children with high functioning autism. The children had prominent pragmatic deficits but relatively preserved structural language skills. The two groups (monolingual, bilingual) were matched for SES (as indexed by maternal education level, Ebert et al. 2019) and full scale IQ (FIQ) using the Wechsler Intelligence Scale (Greek version of the Wechsler Intelligence Scale for Children, Georgas et al. 1997) (see Table 1). Maternal education was calculated on a five-point Likert scale (from 5 that represented the highest educational level attained, to 1 that represented the compulsory primary education) and included the following categories: tertiary, vocational, higher secondary, lower secondary, primary (adapted from UBILEC, see Unsworth 2013). Participants were recruited from schools as well as public and private diagnostic centers. All children in the study had received a diagnosis of ASD from a licensed child psychiatrist or developmental pediatrician, according to the standard diagnostic criteria (ICD-10, DSM-IV, or DSM-V) (American Psychiatric Association 2000, 2013). We confirmed the diagnosis of children with ASD using the Autism Diagnostic Interview-Revised (Rutter et al. 2003). Bilingual children came from mixed marriages and they were exposed to both languages from the time of birth. Thus, they were simultaneous bilinguals. All ASD bilingual children were Albanian-Greek speakers having 2L1s and they were all dominant in Greek. Children's language experience was documented through a comprehensive parental language history questionnaire (see Andreou 2015 for more details) during a typical week of a child's life. The questionnaire identified the home language history (i.e., the child's exposure to each language from birth up to the age of four) and current language use (i.e., literacy and language preference in everyday life with family members or friends) of ASDbi children. Following Andreou (2015) for the analysis of the questionnaire data, points were attributed for input in each language. Points were accumulated based on the number of people interacting with the child at different stages of development. For example, for home language, one or the other language was 
given 1 point, depending on whether a certain family member interacted with the child (father, mother, siblings, grandparents, etc.) in Greek or Albanian, respectively. If a person interacted with the child in both languages, the point was divided between the two languages ( 0.5 points each). This score was normalised (in percentage) for the total number of persons interacting with the child (in one language or another). Table 1 represents the percentage of the scores attributed to the Greek language. Implicitly, the remaining percentage corresponds to the Albanian language. The ages, sex, full-scale IQs, SES, and Autism Diagnostic Interview Revised (ADI-R) scores of the two groups are presented in Table 1. Continuous data in Table 1 are expressed as means and standard deviations (SD), and the categorical data of sex and SES are presented as frequencies and percentages. Univariate tests were calculated with Mann-Whitney non-parametric tests for the continuous variables, and chi-square tests for the categorical variables. The two groups did not differ in any of the background demographic variables. The study was approved by the Research Ethics Committee of the Greek Ministry of Education (Ref. No.: HAA37HAA87) and parental consent was required for participation in the study.

Table 1. Demographic characteristics of monolingual and bilingual children with autism spectrum disorder (ASD).

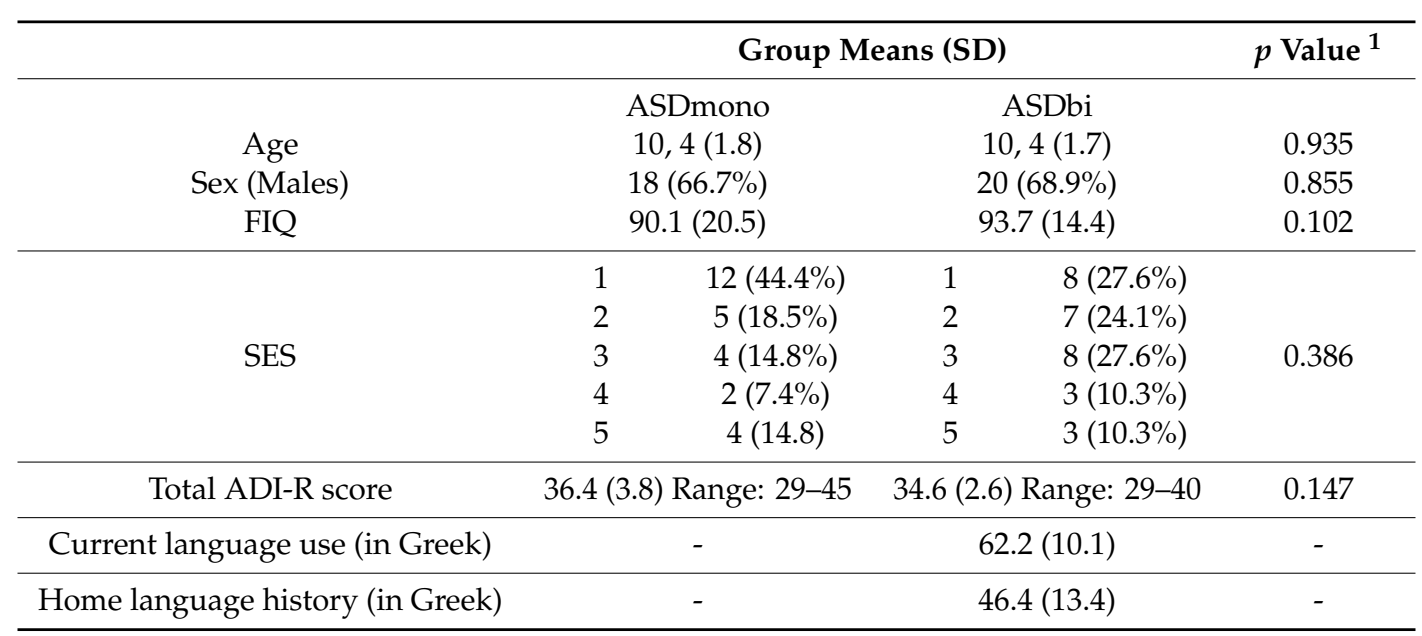

Note. ASD-mono: monolingual children with Autism Spectrum Disorder. ASD-bi: bilingual children with Autism Spectrum Disorder. FIQ: Standard scores from the WISC-III Full Scale IQ scale. SES: socio-economic status. ADI-R: Autism Diagnostic Interview-Revised. ${ }^{1}$ Mann-Whitney-U tests for numerical variables, chi-square tests (Yates correction) for sex.

\subsection{Procedure}

Tests were presented in a randomized order, and scored according to standardized criteria. Both groups of children completed the language ability tasks (expressive vocabulary, sentence repetition), the 2-back task, the verbal ToM tasks (i.e., Sally-Ann, Smarties), and the online, low-verbal ToM during three sessions at the children's home. All assessments were administered in Greek.

\section{Materials}

\subsection{Language Ability Tasks}

\subsubsection{Expressive Vocabulary in Greek}

A standardized expressive vocabulary test (Vogindroukas et al. 2009) was used to measure children's language abilities. This test consists of 50 black-and-white pictures depicting common objects, which each child is required to name. Testing is discontinued when the child fails to respond correctly in five consecutive trials. Each correct response is given one point with a maximum score of 50 points. This test has been standardized with monolingual Greek-speaking children, and, therefore, children's raw scores can be converted into standard scores. 


\subsubsection{Sentence Repetition Task}

To examine children's performance on simple and complex sentences in Greek, we used a sentence repetition task consisting of simple and subordinate structures. For the purposes of this study, we will focus on the subordinate clauses. The task was developed within the COST Action following the guidelines outlined in Marinis and Armon-Lotem (2015). All sentences across different structures were matched for length and word frequency. There were 32 sentences in total.

The novelty of this task is the innovative way of decoding it, placing emphasis on syntactic complexity, and, more specifically, on the distinction between the different types of subordinate clauses, i.e., adverbials, complements, and relatives. Based on our previous work (Peristeri et al. 2017), we assumed that complement clauses rely more extensively on core syntax relative to adverbial clauses, which are rather conditioned at the syntax-discourse interface. Adverbials contain adjuncts that build causal and temporal connections between clauses. As such, they seem to function more as discourse elements and they are not motivated only by syntactic relations (Andreou 2015; Andreou and Tsimpli 2020). The full list of items of the sentence repetition task is included in Andreou (2015, pp. 325-29).

In terms of subordination, the sentence repetition task includes three major types of subordinate clauses: adverbial, complement, and relative clauses. There are five adverbial clauses used in our task. In particular, there was one sentence introduced with the conjunction $p u$ (used for introducing causal, relative adverbial clauses, equivalent to the English 'because'). One sentence introduced with the conjunction eno (used for introducing adverbial concessive clauses, equivalent to the English 'even though') and three sentences introduced with the conjunctions otan/prin/afu (used for introducing temporal adverbial clauses, equivalent to the English when/before/after). There are 11 complement clauses introduced with the following complementizers: oti (used in declarative complements, corresponding to the English complementizer that), pjos and $t i$ (introducing indirect interrogative complements, equivalent to English who or what) and na (a Mood (subjunctive) marker, which introduces verb complements frequently, and is equivalent to infinitival or gerundive complement clauses in English) (Roussou and Tsangalidis 2010). Finally, relatives are a separate category of subordinate clauses that reflect either a complement or adverbial character. There are five complement relative clauses in the task, all introduced with $p u$, an element introducing relative clauses without a relative pronoun (corresponding to the English that used in relatives). Example 1a-1c below illustrate some of the task's adverbial, complement, and relative clauses, respectively.

\section{Example 1.}

a. H yaya Oimotan oti se afta ta meri petusan perier $\gamma$ a pulja.

The. NOM.FEM.SG grandma. NOM.FEM.SG remembered. IMPERF..INDIC. 3P.SG that in these places. ACC.NEUT.PL. were flying. IMPERF..INDIC. 3P.SG weird. NOM.NEUT.PL. birds. NOM.NEUT.PL

"Grandma remembered that in those places, weird birds were flying around"

b. Ekopse to agouri afu kaӨarise kala me nero tis domates.

(She) cut. PAST..INDIC. 3P.SG the. NOM.NEUT.SG. cucumber. NOM.NEUT.SG. after (she) cleaned. PAST..INDIC. 3P.SG well with water the. ACC.FEM.PL tomatoes. ACC.FEM.PL.

"She cut the cucumber after washing the tomatoes well with water."

c. H kaAaristria klotsise ti nosokoma pou v yike apo to grafio.

The. NOM.FEM.SG. cleaning lady. NOM.FEM.SG. kicked.PAST..INDIC. 3P.SG. the. ACC.FEM.SG. nurse. ACC.FEM.SG. that came out. PAST..INDIC. 3P.SG from the office. ACC.NEUT.SG.

"The cleaning lady kicked the nurse that came out of the office." 


\subsection{Coding and Scoring}

Children's performance on the sentence repetition task was scored for overall accuracy and grammaticality. Null responses were excluded from all calculations.

To assess children's accuracy on the task, we used the scoring procedure from the sentence repetition subtest of the Clinical Evaluation of Language Fundamentals (fourth edition) (CELF-4, Semel et al. 2003). According to this scoring scheme, participants are awarded a score of 3 if they made no errors while repeating the sentence, a score of 2 , if they made one error, a score of 1 , if they made two errors, and zero points, if they made three or more errors. An attempt to repeat a sentence was considered to be correct, if it was a verbatim repetition of the target sentence.

We further investigated whether children's utterances remained grammatical despite the different errors. In this analysis, we only included sentences that contained one or more errors and we examined whether or not the child's repetition of the target sentence resulted in an ungrammatical sentence. These types of errors were not structure-specific. For example, in the case of the adverbial (see Example 2a), the substitution of the connective with the conjunction 'and' did not result in an ungrammatical sentence (see Example $2 b$ ). Therefore, in this condition, a sentence containing a connective (instead of a conjunction) remained grammatical. Grammatical sentences were assigned a value of 1 and ungrammatical sentences a value of 0 .

\section{Example 2.}

a. Ekopse to agouri afu kaӨarise kala me nero tis domates.

(She) cut. PAST..INDIC. 3P.SG the. NOM.NEUT.SG. cucumber. NOM.NEUT.SG. after (she)

cleaned. PAST..INDIC. 3P.SG well with water the. ACC.FEM.PL tomatoes. ACC.FEM.PL.

"She cut the cucumber after washing the tomatoes well with water."

b. Ekopse to agouri kai kaAarise kala me nero tis domates.

(She) cut. PAST..INDIC. 3P.SG the. NOM.NEUT.SG. cucumber. NOM.NEUT.SG. and (she)

cleaned. PAST..INDIC. 3P.SG well with water the. ACC.FEM.PL tomatoes. ACC.FEM.PL.

"She cut the cucumber and washed the tomatoes well with water".

\subsection{Procedure}

Children were tested individually in a quiet room at their schools. For the sentence repetition task, children sat in front of a computer screen and listened to the sentences via headphones. All sentences were recorded by a female native speaker of Greek and had normal intonation.

\subsection{2-Back Task}

Children's working memory and updating abilities were measured using a variation of the classic $\mathrm{N}$-back task (Smith and Jonides 1999). In this version, participants viewed a sequence of digits in a computer screen and were instructed to press a certain button when the number on the screen was the same as the one that appeared two trials (2-back) before, and not press any button if the item was different. Children completed 20 practice trials before completing the actual task. Each digit was presented for 500 msecs with an inter-stimulus interval (ISI) of 2500 msecs. Across 60 trials, 20 were the 'correct hit' trials. Accuracy scores (i.e., composite score of the number of corrects hits minus wrong hits) and reaction times (RTs) on correct hits only indexed updating and working memory. 


\section{Theory of Mind Measures}

\subsection{Verbal ToM Tasks}

Unexpected transfer/Sally-Anne task (adapted from 'Sally-Anne Test'-Baron-Cohen et al. 1985). In this task, the experimenter (first author) acted the following sequence using two dolls (a blonde and a brunette), a basket, a box, and a ball, while describing the following events: "Sally is going to put her ball in the basket. Now, Sally is going out to play. While Sally is out, Anne takes the ball out of the basket and puts it in the box. When Sally comes back into the room ... " (the experimenter asks the following questions to the child):

(a) "Where did Sally put the ball?", "Where is the ball really?" (reality control questions)

(b) "Where does Sally believe that the ball is? (first-order false belief question), "Why?" (justification question)

(c) "When Sally comes back into the room, where will she look for her ball first?" (test question), "Why?" (justification question)

For a child's data to be included, he or she was required to respond correctly to the reality control questions. We should note that more than 25 monolingual and bilingual children with ASD that were included in the original cohort have failed to answer correctly to the reality control questions, so they were excluded from the study. For the remaining participants, a child was awarded a score of 2 if he or she made no errors in the reality control questions, while correct responses in the first-order false belief and test questions were scored with 1 point each. The maximum accuracy score was 4 .

Unexpected contents task (adapted from Perner et al. 1989). The unexpected contents task was acted out in two versions, one with the usual Smarties tube and a pencil, and the second with a Band-Aid box and a candy. In the Smarties task, the experimenter showed a Smarties tube to the child and asked:

(a) "What's in here?" (reality control question) The experimenter then said "Let's see what's inside it". The child was shown the true contents of the tube (i.e., a pencil) and told "Look! There is a pencil inside the tube!". The Smarties tube was then closed and the child was asked two questions:

(b) "What did you think was inside the tube before I opened it?" (first-order false belief question)

(c) "Your mother hasn't seen this tube yet. When she comes in later, I'll show her this tube and ask her what's inside. What will she say?" (first-order false belief question); Finally, the experimenter asked the child to justify her/his response.

(d) "Why?" (justification question)

The same procedure was followed for the Band-Aid task. For a child's data to be included, he or she was required to respond correctly to the reality control question. A child was awarded a score of 1 if he or she made no errors in the reality control question, while first-order false belief questions were scored with 2. The justification question was scored with 1 point. The maximum accuracy score for each task was 4 , so the total maximum accuracy score was 8 .

\subsection{Low-Verbal ToM Task}

To assess children's ToM understanding without linguistic or executive confounds, we administered a first-order FB task that reduced linguistic and executive demands as much as possible (see Bloom and German 2000 for discussion). The test was adapted from Forgeot and Ramus (2011). In this task, short video sequences were presented to the participants. There were 10 different short animated stories (henceforth, scenarios) (see http://www.lscp.net/persons/forgeot/stim in Forgeot d'Arc and Ramus's study (2011) for examples and descriptions). Each scenario had a main agent who either had the same belief as the participant or not (Mentalistic). Control (Mechanistic) conditions could be resolved without belief-reasoning, solely on the basis of an accurate grasp of the causal relation between objects. More specifically, videos occurred with either a 'Mentalistic end,' which necessitated attribution of the protagonist's belief and prediction of his action, or a 'Mechanistic end,' which was 
based only on the understanding and prediction of an event in the physical world without belief attribution. In the 'Watering plant' scenario of the task, for example, the participant views a man (the main agent) standing between two pots with one on his left and one on his right. When the man is done watering the pot on his left, he goes on to water the pot on his right but discovers that the watering can has no more water. The man then moves towards a tap, holds the watering can under the tap, and waits for the water to fill up to the top. While he is filling in the watering can and not looking at the pots, another man appears to switch the places of the two pots before leaving the scene. The change in the location of the two pots is either witnessed (seen condition) or not (unseen condition) by the main agent, who, after filling the watering can, moves into the forefront and stands between the two pots. There are two different endings for each of these conditions. The mentalistic ending depicts the main agent watering the pot on his right or on his left, while the mechanistic ending depicts the main agent standing between the two pots, and the left or the right pot overflowing. At the end of the video of each scenario, the child is presented with a question mark [?] on the center of the screen and is asked to decide as quickly and as accurately as possible whether the ending shown is the most appropriate ending for that story. There is a total of 100 video trials, while 10 trials are used in the familiarization phase. The task was built with E-Prime software (Schneider et al. 2012). Response times (RT) (i.e., time in msecs from the presentation of the question mark to the child's button-press) and accuracy $(\%)$ of judgments were recorded.

\subsection{Analysis Plan}

First, a one-way between-subject analysis of variance (ANOVA) was performed on children's expressive vocabulary scores. Next, in order to investigate possible bilingualism effects on the children's sentence repetition scores, logit mixed effects models were performed separately for the grammaticality and the accuracy measure. Besides the analyses on the children's total repetition scores, logit mixed effects models were performed separately for simple and subordinate clauses as well as the different subordinate clause types, which were included in the test, namely, complement, relative, and adverbial clauses. Language experience (monolinguals, bilinguals) was the predictor in each model, while participants were the random slopes. Age and expressive vocabulary were also included as predictors in all models. Further logit mixed effects models were performed for the 2-back task, the verbal ToM tasks, and the low-verbal ToM task.

As a final step, and in order to examine the contribution of EF and sentence repetition to ToM performance, we ran a series of linear regressions. Predictors were entered in a single step and included: total sentence repetition scores, scores in simple and subordinate clauses, complement, relative, and adverbial clauses (in both the grammaticality and the accuracy measure). The dependent variables, on the other hand, included scores in the verbal ToM tasks, and accuracy and RT in the mechanistic and mentalistic conditions of the low-verbal ToM task. The regressions were conducted separately by group. The models were fitted in $\mathrm{R}$ using the lmer function from the lme4 package (Bates and Maechler 2010).

\section{Results}

\subsection{Language Ability Screening Tasks}

Table 2 below presents the groups' mean scores on expressive vocabulary. A one-way ANOVA analysis showed a significant group effect for expressive vocabulary, $\mathrm{F}(1,55)=11.173, p=0.002$, $\eta 2=0.41$, which stemmed from the fact that ASDbi children scored significantly lower than their ASDmono peers in the specific test. 
Table 2. Expressive vocabulary performance in monolingual and bilingual children with autism spectrum disorder (ASD).

\begin{tabular}{lccccccc}
\hline & \multicolumn{3}{c}{ ASDmono } & \multicolumn{3}{c}{ ASDbi } \\
\cline { 2 - 8 } & Mean & SD & Range & Mean & SD & Range \\
\hline Expressive vocabulary & 37.7 & 5.6 & $25-47$ & 31.6 & 7.8 & $11-46$ \\
\hline
\end{tabular}

Note. ASDmono: monolingual children with Autism Spectrum Disorder. ASDbi: bilingual children with Autism Spectrum Disorder.

Table 3 illustrates the descriptive data of each group's grammaticality and accuracy performance in the sentence repetition task. Analyses were performed on total sentence repetition scores as well as scores on simple and subordinate clauses, separately for grammaticality and accuracy. Children's scores were also split by the type of clause (complement, relative, adverbial) and further analyses were performed on each type. Tables 4 and 5 present the results of the mixed effects models for grammaticality and accuracy, respectivelyOn the other hand, the mixed effects models on accuracy revealed significant Language experience effects for the total sentence repetition score as well as subordinate clauses, relatives, and adverbials. The effects stemmed from the fact that the ASDbi children exhibited higher accuracy scores in sentence repetition (collapsing across sentence-types) and repeated more accurately subordinate clauses—relatives and especially adverbials-than the ASDmono group. In addition, there was a significant effect of age on the total accuracy score.

Table 3. Sentence repetition performance means (and SD) in monolingual and bilingual children with autism spectrum disorder (ASD).

\begin{tabular}{ccccc}
\hline & & ASDmono & ASDbi \\
\hline \multirow{2}{*}{ Total score } & & Grammaticality (max. score: 33) & $29.8(1.9)$ & $28.6(3.6)$ \\
& & Accuracy (max. score: 99) & $56.2(17.7)$ & $68.7(18.6)$ \\
\hline \multirow{2}{*}{ Simple clauses } & & Grammaticality (max. score: 12) & $10.4(1.3)$ & $10.2(1.6)$ \\
& & Accuracy (max. score: 36) & $20.9(9.6)$ & $24.9(6.6)$ \\
\hline \multirow{3}{*}{ Complement } & Grammaticality (max. score: 21) & $16.9(2.7)$ & $17.0(3.3)$ \\
& & Accuracy (max. score: 63) & $32.6(19.5)$ & $41.0(14.5)$ \\
& & Grammaticality (max. score: 11) & $9.5(1.1)$ & $8.9(1.6)$ \\
& & Accuracy (max. score: 33) & $18.8(10.0)$ & $21.8(6.3)$ \\
\cline { 2 - 5 } & \multirow{2}{*}{ Relative } & Grammaticality (max. score: 5) & $4.5(0.8)$ & $4.4(0.9)$ \\
& & Accuracy (max. score: 15) & $8.8(5.0)$ & $11.1(3.7)$ \\
\cline { 2 - 5 } & \multirow{2}{*}{ Adverbial } & Grammaticality (max. score: 5) & $4.7(0.7)$ & $4.8(0.6)$ \\
& & Accuracy (max. score: 15) & $7.7(4.2)$ & $10.8(3.0)$ \\
\hline
\end{tabular}

Note. ASDmono: monolingual children with Autism Spectrum Disorder. ASDbi: bilingual children with Autism Spectrum Disorder. max.: maximum.

\subsection{Executive Function Task}

Table 6 below presents ASDmono and ASDbi children's accuracy scores in the two-back working memory and updating task. The mixed effects model revealed a significant effect for language experience, which stemmed from the fact that the ASDbi group scored significantly higher than the ASDmono group in the composite accuracy measure of the two-back task (see Table 7).

\subsection{Verbal ToM tasks}

Table 8 below illustrates ASDmono and ASDbi children's accuracy scores in the verbal ToM tasks (i.e., Sally-Ann, Smarties). The mixed effects model revealed no significant effect for language experience on the Sally-Ann and the Smarties tests (see Table 9). 
Table 4. Summary of logit mixed effects models for grammaticality in sentence repetition: Total scores, simple vs. subordinate clauses, and clause-types.

\begin{tabular}{|c|c|c|c|c|c|c|c|c|c|c|c|c|c|c|c|c|c|c|c|c|c|c|c|c|}
\hline \multirow[t]{2}{*}{ Predictors } & \multicolumn{4}{|c|}{ Total Score } & \multicolumn{4}{|c|}{ Simple Clauses } & \multicolumn{4}{|c|}{ Subordinate Clauses } & \multicolumn{4}{|c|}{ Complement Clauses } & \multicolumn{4}{|c|}{ Relative Clauses } & \multicolumn{4}{|c|}{ Adverbial Clauses } \\
\hline & Coefficient & SE & $\mathbf{z}$ & $\begin{array}{c}p \\
\text { Value }\end{array}$ & Coefficient & SE & $\mathrm{z}$ & $\begin{array}{c}p \\
\text { Value }\end{array}$ & Coefficient & SE & $\mathrm{z}$ & $\begin{array}{c}p \\
\text { Value }\end{array}$ & Coefficient & $\mathrm{SE}$ & $\mathrm{z}$ & $\begin{array}{c}p \\
\text { Value }\end{array}$ & Coefficient & $\mathrm{SE}$ & $\mathrm{z}$ & $\begin{array}{c}p \\
\text { Value }\end{array}$ & Coefficient & SE & $\mathrm{z}$ & $\begin{array}{c}p \\
\text { Value }\end{array}$ \\
\hline Intercept & 13.27 & 18.28 & 0.73 & 0.472 & 6.58 & 9.82 & 0.67 & 0.506 & -6.61 & 20.03 & -3.30 & 0.743 & 2.23 & 8.86 & -0.25 & 0.802 & -2.44 & 5.55 & -0.44 & 0.662 & 7.04 & 3.96 & 1.77 & 0.082 \\
\hline $\begin{array}{c}\text { Language } \\
\text { experience }\end{array}$ & -23.14 & 29.74 & -0.77 & 0.440 & -4.43 & 15.97 & -0.27 & 0.782 & 35.24 & 32.57 & 1.08 & 0.285 & 13.43 & 14.42 & 9.32 & 0.356 & -4.19 & 9.03 & -0.46 & 0.644 & 10.32 & 6.44 & 1.60 & 0.116 \\
\hline Age & -0.71 & 1.86 & -0.38 & 0.706 & -0.04 & 1.00 & -0.39 & 0.969 & 0.08 & 2.04 & 0.382 & 0.704 & 0.87 & 0.90 & 0.970 & 0.337 & 0.07 & 0.57 & 0.12 & 0.905 & 0.31 & 0.40 & 0.77 & 0.444 \\
\hline $\begin{array}{l}\text { Expressive } \\
\text { vocabulary }\end{array}$ & -0.67 & 0.56 & -1.19 & 0.237 & -0.20 & 0.30 & -0.66 & 0.508 & 0.64 & 0.61 & 1.05 & 0.299 & 0.47 & 0.27 & 1.72 & 0.041 * & 0.08 & 0.17 & 0.44 & 0.660 & -0.05 & 0.12 & -0.38 & 0.705 \\
\hline
\end{tabular}

Note: $\mathrm{SE}=$ standard error. Language experience levels: Monolingual vs. Bilingual. Reference level for Language experience: Monolingual. ${ }^{*} p<0.05$

Table 5. Summary of logit mixed effects models for accuracy in sentence repetition: Total scores, simple vs. subordinate clauses, and clause-types.

\begin{tabular}{|c|c|c|c|c|c|c|c|c|c|c|c|c|c|c|c|c|c|c|c|c|c|c|c|c|}
\hline \multirow{2}{*}{ Predictors } & \multicolumn{4}{|c|}{ Total Score } & \multicolumn{4}{|c|}{ Simple Clauses } & \multicolumn{4}{|c|}{ Subordinate Clauses } & \multicolumn{4}{|c|}{ Complement Clauses } & \multicolumn{4}{|c|}{ Relative Clauses } & \multicolumn{4}{|c|}{ Adverbial Clauses } \\
\hline & Coefficient & $\mathrm{SE}$ & $\mathrm{z}$ & $\begin{array}{c}p \\
\text { Valsue }\end{array}$ & Coefficient & SE & $\mathrm{z}$ & $\begin{array}{c}p \\
\text { Value }\end{array}$ & Coefficient & SE & $\mathrm{z}$ & $\begin{array}{c}p \\
\text { Value }\end{array}$ & Coefficient & SE & $\mathrm{z}$ & $\begin{array}{c}p \\
\text { Value }\end{array}$ & Coefficient & SE & $\mathrm{z}$ & $\begin{array}{c}p \\
\text { Value }\end{array}$ & Coefficient & SE & $\mathrm{z}$ & $\begin{array}{c}p \\
\text { Value }\end{array}$ \\
\hline Intercept & 68.72 & 4.34 & 15.79 & $\underset{* * 0.001}{<* *}$ & 24.96 & 1.52 & 16.37 & $<<_{* * *} 0.001$ & -41.03 & 3.17 & -12.91 & $<0.001$ & 21.89 & 1.54 & -14.14 & $<0.001$ & -11.10 & 0.81 & -13.57 & $<0.001$ & 10.75 & 0.67 & 15.85 & $<0.001$ \\
\hline $\begin{array}{l}\text { Language } \\
\text { experience }\end{array}$ & -12.50 & 6.26 & -1.99 & $0.05^{*}$ & -4.03 & 2.19 & -1.84 & 0.071 & 8.44 & 4.57 & 1.84 & $0.051 *$ & 3.08 & 2.22 & 1.38 & 0.173 & -2.32 & 1.17 & -1.97 & $0.05^{*}$ & 3.05 & 0.97 & 3.12 & $0.003^{*}$ \\
\hline Age & -7.89 & 16.64 & -0.47 & 0.637 & $-0.04^{*}$ & 1.94 & -0.34 & 0.736 & 5.41 & 11.88 & 0.45 & 0.651 & 2.69 & 5.89 & 0.45 & 0.650 & 2.32 & 3.16 & 0.73 & 0.466 & 0.93 & 2.59 & 0.36 & 0.720 \\
\hline $\begin{array}{l}\text { Expressive } \\
\text { vocabulary }\end{array}$ & -3.50 & 5.01 & -0.69 & 0.489 & -1.00 & 1.72 & -0.58 & 0.562 & 2.65 & 3.58 & 0.74 & 0.462 & 1.15 & 1.77 & 0.64 & 0.520 & 0.82 & 0.95 & 0.86 & 0.391 & -0.51 & 0.78 & -0.66 & 0.512 \\
\hline
\end{tabular}

Note. SE $=$ standard error. Language experience levels: Monolingual vs. Bilingual. Reference level for Language experience: Monolingual. ${ }^{*} p<0.05,{ }^{* * *} p<0.001$. 
Table 6. Groups' mean composite accuracy scores (\%) in the two-back task.

\begin{tabular}{cc}
\hline Group & Two-Back Accuracy (\%) (SD) \\
\hline ASDmono & $24.2(17.8)$ \\
ASDbi & $43.4(13.5)$ \\
\hline
\end{tabular}

Note. ASDmono: monolingual children with Autism Spectrum Disorder. ASDbi: bilingual children with Autism Spectrum Disorder.

Table 7. Summary of logit mixed effects model: Composite accuracy in the two-back task.

\begin{tabular}{ccccc}
\hline Predictors & Coefficient & SE & $\mathbf{z}$ & $p$ Value \\
\hline Intercept & 43.41 & 4.77 & 9.1 & $<0.001^{* * *}$ \\
Language experience & 19.15 & 6.87 & 2.78 & $0.007^{* *}$ \\
Age & 2.55 & 2.81 & 0.91 & 0.369 \\
\hline
\end{tabular}

Note: $\mathrm{SE}=$ standard error. Language experience levels: Monolingual vs. Bilingual. Reference level for Language experience: Monolingual. ${ }^{* *} p<0.01,{ }^{* * *} p<0.001$.

Table 8. Groups' mean accuracy scores in the verbal theory of mind tasks.

\begin{tabular}{ccc}
\hline Group & Sally-Ann (SD) Range & Smarties (SD) Range \\
\hline ASDmono & $2.9(1.0) 2-4$ & $6.7(1.4) 5-8$ \\
\hline ASDbi & $3.2(0.9) 2-4$ & $6.6(2.2) 2-8$ \\
\hline
\end{tabular}

Note. ASDmono: monolingual children with Autism Spectrum Disorder. ASDbi: bilingual children with Autism Spectrum Disorder.

Table 9. Summary of logit mixed effects models: Verbal Theory of Mind tasks.

\begin{tabular}{ccccccccc}
\hline Predictors & \multicolumn{4}{c}{ Sally-Ann } & \multicolumn{3}{c}{ Smarties } \\
& Coefficient & SE & $\mathbf{z}$ & $p$ Value & Coefficient & SE & $\mathbf{z}$ & $p$ Value \\
\hline Intercept & 3.23 & 6.70 & 0.48 & 0.632 & 14.67 & 13.06 & 1.12 & 0.267 \\
Language experience & 3.12 & 10.91 & 2.86 & 0.776 & 2.75 & 21.24 & 0.129 & 0.898 \\
Age & 0.03 & 0.68 & 0.05 & 0.959 & 1.01 & 1.33 & 0.759 & 0.452 \\
Expressive vocabulary & 0.02 & 0.20 & 0.07 & 0.948 & 0.24 & 0.40 & 0.62 & 0.539 \\
\hline
\end{tabular}

Note. SE = standard error. Language experience levels: Monolingual vs. Bilingual. Reference level for Language experience: Monolingual.

\subsection{Low-Verbal ToM Task}

Table 10 below illustrates ASDmono and ASDbi children's accuracy scores in the accuracy and the RT measures of the mechanistic and mentalistic trials of the online low-verbal ToM task. The mixed effects model revealed no significant effect for language experience on the mechanistic trials of the task in either the accuracy or the RT measure. Yet, there was a significant language experience effect on accuracy in the mentalistic trials, which stemmed from ASDbi children's higher accuracy score than the ASDmono group (see Table 11).

Table 10. Groups' mean accuracy scores and RT in the low-verbal Theory of Mind task.

\begin{tabular}{clcc}
\hline Group & Measure & Mechanistic Trials & Mentalistic Trials \\
\hline ASDmono & Accuracy & $88.5(10.3)$ & $54.4(16.7)$ \\
& RT & $2150(536)$ & $2974(576)$ \\
ASDbi & Accuracy & $86.5(8.2)$ & $75.4(13.2)$ \\
& RT & $1887(584)$ & $2751(447)$ \\
\hline
\end{tabular}

Note. ASDmono: monolingual children with Autism Spectrum Disorder. ASDbi: bilingual children with Autism Spectrum Disorder. RT = reaction time. 
Table 11. Summary of logit mixed effects models: Low-verbal Theory of Mind task.

\begin{tabular}{|c|c|c|c|c|c|c|c|c|c|c|c|c|c|c|c|c|}
\hline \multirow[t]{3}{*}{ Predictors } & \multicolumn{8}{|c|}{ Accuracy } & \multicolumn{8}{|c|}{ Reaction Times } \\
\hline & \multicolumn{4}{|c|}{ Mechanistic Trials } & \multicolumn{4}{|c|}{ Mentalistic Trials } & \multicolumn{4}{|c|}{ Mechanistic Trials } & \multicolumn{4}{|c|}{ Mentalistic Trials } \\
\hline & Coefficient & SE & $\mathbf{z}$ & $p$ Value & Coefficient & SE & $\mathbf{z}$ & $p$ Value & Coefficient & SE & $\mathrm{z}$ & $p$ Value & Coefficient & SE & $\mathrm{z}$ & $p$ Value \\
\hline Intercept & 77.29 & 10.67 & 7.23 & $\underset{* * *}{<0.001}$ & 75.41 & 2.80 & 26.92 & $\underset{* * *}{<0.001}$ & 2129.96 & 12.4426 & 1.71 & 0.093 & 3901.54 & 1365.86 & 2.85 & $0.006^{* *}$ \\
\hline $\begin{array}{l}\text { Language } \\
\text { experience }\end{array}$ & 3.37 & 14.90 & 0.22 & 0.822 & 21.00 & 4.03 & 5.20 & $\underset{* * *}{<0.001}$ & 209.50 & 1736.13 & 0.12 & 0.904 & 1260.48 & 1905.80 & 0.66 & 0.511 \\
\hline Age & 0.88 & 1.01 & 0.87 & 0.384 & 0.02 & 1.67 & 0.02 & 0.990 & 23.27 & 117.99 & 0.20 & 0.844 & 110.52 & 129.52 & 0.85 & 0.397 \\
\hline
\end{tabular}

Note. SE $=$ standard error. Language experience levels: Monolingual vs. Bilingual. Reference level for Language experience: Monolingual. ${ }^{* *} p<0.01,{ }^{* * *} p<0.001$. 


\subsection{Links between Theory of Mind Performance, Executive Functions, and Sentence Repetition}

The linear regression analysis tested the links of verbal and low-verbal ToM tasks with executive functions and language ability as expressed through the children's sentence repetition ability in each group.

For the ASDmono group, the overall model was significant for the Smarties task, $\mathrm{F}(3,26)=2.927$, $p=0.05, \mathrm{R} 2=0.28$. A single predictor accounted for significant independent variance in the model, namely, accuracy in the complement clause repetition, $\beta=0.725, p=0.031$. There were no significant models for the Sally-Ann, $\mathrm{F}(3,26)=1.218, p=0.326$, and the low-verbal ToM task (in either the accuracy or the RT measure), $\mathrm{F}(3,26)=1.197, p=0.331$.

For the ASDbi group, the overall model was significant for the Sally-Ann, $F(3,28)=3.535$, $p=0.029 ; \mathrm{R} 2=0.30$, and the low-verbal ToM task, $\mathrm{F}(3,28)=3.504, p=0.032, \mathrm{R} 2=0.32$. In both models, two predictors accounted for significant independent variance: two-back accuracy, $\beta=0.783$, $p=0.011$, and adverbial clause repetition, $\beta=0.754, p=0.014$, for the Sally Ann task, two-back accuracy, $\beta=0.439, p=0.020$, and adverbial clause repetition, $\beta=3.337, p=0.042$, for the low-verbal ToM task. The model for the Smarties task was not found to be significant, $\mathrm{F}(3,28)=0.336, p=0.799$.

\section{Discussion}

The present study investigated bilingualism effects in the verbal and low-verbal ToM performance of children with ASD. For this purpose, we have tested 27 monolingual and 29 bilingual children with ASD. The same children were also administered EF and sentence repetition tasks to assess the extent to which their ToM performance would be affected by cognitive control and/or language ability factors. According to the results, bilingual children with ASD exhibited superior performance in comparison to the monolingual group with ASD in the low-verbal ToM and the two-back task. With respect to the sentence repetition task, the results show that the bilingual group scored higher than monolinguals in syntactically complex sentences, and specifically in adverbials and relatives. Regarding the links between ToM performance, $\mathrm{EF}$, and sentence repetition, the pattern of results suggests that mentalizing followed distinct pathways across the two groups.

In particular, monolingual children with ASD seemed to rely mostly on syntax while performing a verbal ToM task, whereas bilingual children with ASD drew on EF and adverbial clause repetition while performing both verbal and low-verbal ToM tasks. Investigating how these two types of skills (i.e., EF and adverbials) underlie ToM skills in bilingual children with ASD is challenging, especially since the low-verbal ToM task involved a minimum amount of language all the same. We assume that the verbal ToM tasks include a stage of semantic and syntactic processing associated with the meaning integration, while both the verbal and low-verbal ToM tasks include a belief attribution stage that involves efficient reasoning about the beliefs of an agent other than the self. The monolingual children with ASD may have had better access to the language properties of the lexical concepts and, thus, would more readily rely on their core language skills in the belief attribution stage of the verbal ToM tasks. In contrast, the bilingual group with ASD was better than the monolingual group deriving the belief of the nonverbal scenarios' protagonists, when language contents were kept to a minimum and aspects of the scenarios were highly imagistic. The effects of adverbial clauses on ToM performance suggests that grasp of the particular type of subordinate clause made belief attribution easier for the bilingual group with ASD, especially when mentalizing concepts were nonverbal. Considered in light of theories on the role of adverbials as the linguistic marker of coherence in pragmatics (Diessel 2001; Lust et al. 2015; Tomasello 2003), these data point to an interesting relation between the grasp of adverbials and ToM skills, even when the latter are not mediated by tasks that are highly verbal. Our results are in line with previous findings of studies (Andreou 2015; Andreou and Tsimpli 2020) that dealt with bilingual TD children's production of subordinate clauses and found differences in performance across the types of subordinates. In particular, they demonstrated that TD bilingual children were more efficient in the production of adverbial (vs. complement) clauses in comparison to their TD monolingual peers. This difference was attributed to the fact that complement clauses belong 
to core grammar and depend more on language-specific properties, whereas adverbial clauses are an index of cohesion. They are, therefore, more transferable between the languages of the bilingual child at some conceptual level having, as a prerequisite, that a basic linguistic knowledge is already established.

Our first research question was whether the monolingual and bilingual groups with ASD would differ in the verbal and low-verbal ToM tasks as well as in the EF and sentence repetition tasks. Our results revealed no significant group effect in neither of the two verbal ToM tasks. Although this may appear as a surprising result, the reader should bear in mind that the study's population consisted of simultaneous bilinguals who were dominant in the language they were tested, i.e., Greek. Our bilingual group with ASD attended Greek monolingual schools, which might account for the lack of group differences in the two verbal ToM tasks. Furthermore, the typological similarity between the children's L1s, namely, Albanian and Greek, may have boosted children's language processing skills in Greek. Thus, these bilinguals managed to perform at similar levels with their monolingual peers with ASD. In addition, the lack of group differences in the verbal ToM tasks may be attributed to the fact that the two tasks are relatively simple tasks for children within the age range (i.e., $7-15$ years) in the current study. In fact, first-order ToM skills are often reported to be mastered around the mental age of 6 for children with ASD (e.g., Fisher et al. 2005; Happé 1995).

However, when it comes to the low-verbal ToM task, the picture is different since the bilingual group with ASD outperformed their monolingual peers in the accuracy measure of the task's mentalistic trials. The verbal load of the ToM tasks distinguished between the two groups, implying that this asymmetry may be attributed to the language demands of the unexpected transfer and unexpected content tasks that have been extensively reported to compromise children's performance in mentalizing tasks (e.g., Burnel et al. 2018; Durrleman 2020; Durrleman and Franck 2015; Peristeri et al. 2020). Interestingly, the two groups did not differ in the accuracy measure of the low-verbal ToM task's mechanistic condition ( $>75 \%$ accuracy for both groups), which suggests that the children with ASD had an accurate understanding of what they were perceiving physically, and that the locus of impairment for the monolingual children with ASD lied in their ability to navigate the social world and not the physical environment.

The two-back EF test revealed striking differences between the two groups, since bilingual ASD children's accuracy level was at least double relative to their monolingual peers. These results show that bilingualism can compensate for working memory deficits in ASD (e.g., Sinzig et al. 2008; Williams et al. 2005). Though it is hard to evaluate the specific aspect of working memory (inhibition of interference, attention shifting, and updating) that has been affected by bilingualism in the task, we hypothesize that bilingual children with ASD were more efficient than monolinguals during encoding and retrieving the target digits.

Performance on the sentence repetition task was measured in terms of grammaticality and accuracy. While the two groups achieved similar levels of performance in grammaticality, the bilingual children with ASD exhibited higher scores than their monolingual peers in accuracy on modifier clauses, namely adverbials and relatives. This was an unexpected result. However, this pattern of results may be accounted for by a variety of factors related to the ASD children's bilingual and clinical profile, such as the fact that the children had 2L1s. They were dominant in Greek, they attended Greek monolingual schools, and they were high-functioning. Another factor that may have accounted for this finding has to do with the linguistic proximity between the two languages of the bilinguals. Andreou and Tsimpli (2020) found that Greek monolingual and Greek-Albanian children had similar performance in narration since they produced higher numbers of complex sentences and complement clauses compared to the Greek-German and Greek-English bilingual groups. The authors claimed that typological proximity paves the ground for stronger cross-linguistic influence. Since Greek and Albanian are two languages with common morphosyntactic features, this may be the reason why bilingual children with ASD achieved high performance in the sentence repetition task. An alternative explanation may have also been their high performance in the two-back task. Despite the sentence repetition test's extensive use across a variety of impaired and non-impaired 
child populations, it still remains unclear whether the specific task measures EF (Baddeley 2012), language abilities (Klem et al. 2015), or both (Polišenská et al. 2015). It seems that the bilingual group's advantage in the two-back task boosted performance in modifier clause repetition, despite the bilingual children's lower expressive vocabulary skills relative to monolingual children with ASD. Bilingualism, therefore, played a compensatory role for ASD children's difficulties in syntactic complexity. Similarly, Andreou and Tsimpli (2020)'s narrative study found that TD bilingual children outperformed their TD monolingual peers in the use of adverbial clauses in a retelling task, despite bilingual children's lower expressive vocabulary skills. Furthermore, as already mentioned, performance in adverbials in Andreou and Tsimpli's (2020) study was driven by TD bilingual children's higher EF skills tested through the two-back test (see Andreou 2015 for more details). In the current study, bilingualism's selective boost of the modifier (vs. complement) clauses of the repetition task may be attributed to the function that the particular clauses serve in language. Specifically, modifier clauses serve the function of the pragmatic organization of a complex sentence, which is not wholly tied to the syntactic requirements of the immediate linguistic context. If bilingualism helped children with ASD to be better tuned to the information expressed in modifier clauses, then this may explain why bilingual children with ASD outperformed their monolingual peers in the specific clause-types of the sentence repetition task.

Our second aim was to explore how monolingual and bilingual ASD children's EF and sentence repetition skills were linked to their performance in the verbal and low-verbal ToM task. As already mentioned, the results indicate different interactions across groups. Specifically, monolingual ASD children's performance in the Smarties task was associated with their accuracy in complement clause repetition. This finding is in line with de Villiers' $(2000,2007)$ findings of strong links between the syntax of complementation and meta-representational cognitive capacities in children. On the other hand, bilingual ASD children's performance in the Sally-Ann and the low-verbal ToM task was predicted by the children's EF and adverbial clause repetition performance. As such, EF and language pragmatics appeared to be more relevant for ToM in the bilingual group with ASD than their monolingual peers, who appeared to mostly rely on syntax, representing different pathways of mentalizing from the bilingual group. The finding that EF were related to ToM performance in bilingual but not in monolingual children with ASD aligns with results of bilingual TD children (e.g., Buac and Kaushanskaya 2020; Nguyen and Astington 2014).

Language abilities were found to be associated with the bilingual ASD children's performance in the low-verbal ToM task. This implies that successful ToM reasoning operates on mental representations which are actually linguistic in nature and constitute the 'language of thought' (Çokal et al. 2018; Hinzen and Sheehan 2013; Hinzen and Rosselló 2015). In this sense, both low-verbal and highly-verbal ToM tasks involve linguistic representations that occur in mental language. The finding that language and nonverbal ToM intersect has received support from previous research. Deaf children in hearing families that did not use sign language as a means of communication with their children, showed a considerable delay in their nonverbal ToM abilities. On the contrary, deaf children, who did acquire sign language, did not show such a delay (Schick et al. 2007). Patients with aphasia have also been shown to face nonverbal ToM deficits that correlate with their language impairment (Varley and Siegal 2000).

At this point, certain limitations regarding our study should be acknowledged. First, the study involved a small number of participants. Thus, certain links between ToM, EF, and language ability in children with ASD may have been undetectable. Second, the study did not include data from TD children that could have shed light on how patterns of performance in ToM deviate between monolingual and bilingual children with and without autism. This indicates a need for future studies with larger samples of bilingual children with ASD and age-matched TD peers to further investigate bilingualism effects in cognition in autism. 


\section{Concluding Remarks}

The overall findings of this study show that bilingualism has a positive effect on the mentalizing skills of children with ASD, which is in line with other preliminary work on this topic (Baldimtsi et al. 2020; Peristeri et al. 2020). Furthermore, the study contributed to the identification of both linguistic and cognitive markers of the ToM advantage in bilingual children with ASD. More specifically, EF and language pragmatics, rather than the syntax of complementation, were significant predictors of bilingual ASD children's success at ToM tasks. Beyond the scientific implications of these results for the language-cognition interface, they are also important on a societal level. Many parents and caregivers of children on the spectrum fear negative repercussions of bilingualism (Beauchamp and MacLeod 2017; Hampton et al. 2017). Our work suggests that this fear is unfounded, at least for subgroups on the spectrum such as those examined here, and moreover illustrates that certain cognitive and communicative challenges associated with ASD may be alleviated by the bilingual experience. If future work with larger cohorts replicates our findings on the interaction between language ability, executive functions, and ToM in bilingual children with ASD, we will be in a better position to address the pressing needs of the autism community to take evidence-based decisions regarding bilingualism.

Author Contributions: Conceptualization, M.A., I.M.T., S.D., and E.P. Formal analysis, M.A. and E.P. Data curation, M.A. and E.P. Writing—original draft preparation, M.A. and E.P. Writing—review and editing, M.A., I.M.T., S.D., and E.P. All authors have read and agreed to the published version of the manuscript.

Funding: This research received no external funding.

Conflicts of Interest: The authors declare no conflict of interest.

\section{References}

Adesope, Olusola O., Tracy Lavin, Terri Thompson, and Charles Ungerleider. 2010. A systematic review and meta-analysis of the cognitive correlates of bilingualism. Review of Educational Research 80: 207-45. [CrossRef]

American Psychiatric Association. 2000. Diagnostic and Statistical Manual of Mental Disorders: DSM-IV, 4th ed. Washington, DC: American Psychiatric Publishing.

American Psychiatric Association. 2013. Diagnostic and Statistical Manual of Mental Disorders: DSM-5, 5th ed. Washington, DC: American Psychiatric Publishing.

Andreou, Maria. 2015. The Effects of Bilingualism on Verbal and Non Verbal Cognition: The Micro-and MacroStructure of Narratives in the Weak and the Dominant Language of the Bilingual Child. Ph.D. dissertation, Aristotle University of Thessaloniki, Thessaloniki, Greece. Unpublished.

Andreou, Maria, and Ianthi M. Tsimpli. 2020. Bilingualism, biliteracy and syntactic complexity: The role of crosslinguistic influence and cognitive skills. Language Acquisition, Processing and Bilingualism: Selected Papers from the Romance Turn 7: 132.

Asakura, Nobuhiko, and Toshio Inui. 2016. A Bayesian Framework for False Belief Reasoning in Children: A Rational Integration of Theory-Theory and Simulation Theory. Frontiers in Psychology. [CrossRef]

Astington, Janet W., and Jeniffer M. Jenkins. 1999. A longitudinal study of the relation between language and theory-of-mind development. Developmental Psychology 35: 1311. [CrossRef] [PubMed]

Astington, Janet W., Janette Pelletier, and Bruce Homer. 2002. Theory of mind and epistemological development: The relation between children's second-order false-belief understanding and their ability to reason about evidence. New Ideas in Psychology 20: 131-44. [CrossRef]

Baddeley, Alan. 2012. Working memory: Theories, models, and controversies. Annual Review of Psychology 63: 1-29. [CrossRef]

Baldimtsi, Eleni, Eleni Peristeri, Ianthi M. Tsimpli, and Stephanie Durrleman. 2020. The impact of bilingualism in theory of mind and executive functions in typically-developing children and children with autism spectrum disorders. In Proceedings of the 44th annual Boston University Conference on Language Development. Edited by Megan M. Brown and Alexandra Kohut. Somerville: Cascadilla Press, vol. 1, pp. 40-52.

Baron-Cohen, Simon. 1991. Do people with autism understand what causes emotion? Child Development 62: 385-95. [CrossRef] 
Baron-Cohen, Simon, Alan M. Leslie, and Uta Frith. 1985. Does the autistic child have a "theory of mind"? Cognition 21: 37-46. [CrossRef]

Baron-Cohen, Simon, Sally Wheelwright, Jacqueline Hill, Yogini Raste, and Ian Plumb. 2001. The "Reading the Mind in the Eyes" Test revised version: A study with normal adults, and adults with Asperger syndrome or highfunctioning autism. The Journal of Child Psychology and Psychiatry and Allied Disciplines 42: 241-51. [CrossRef]

Bates, Douglas, and Martin Maechler. 2010. Matrix: Sparse and Dense Matrix Classes and Methods. R Package Version 0.999375-43. Available online: http://cran.r-project.org/package=Matrix (accessed on 15 March 2017).

Beauchamp, Myriam L., and Andrea A. MacLeod. 2017. Bilingualism in children with autism spectrum disorder: Making evidence based recommendations. Canadian Psychology/Psychologie Canadienne 58: 250. [CrossRef]

Bedore, Lisa M., Elizabeth D. Peña, Connie L. Summers, Karin M. Boerger, Maria D. Resendiz, Kai Greene, Thomas M. Bohman, and Ronald B. Gillam. 2012. The measure matters: Language dominance profiles across measures in Spanish-English bilingual children. Bilingualism (Cambridge, England) 15: 616. [CrossRef]

Bialystok, Ellen. 2015. Bilingualism and the development of executive function: The role of attention. Child Development Perspectives 9: 117-21. [CrossRef] [PubMed]

Bloom, Paul, and Tim P. German. 2000. Two reasons to abandon the false belief task as a test of theory of mind. Cognition 77: 25-31. [CrossRef]

Bodner, Kimberly E., Christopher R. Engelhardt, Nancy J. Minshew, and Diane L. Williams. 2015. Making inferences: Comprehension of physical causality, intentionality, and emotions in discourse by high-functioning older children, adolescents, and adults with autism. Journal of Autism and Developmental Disorders 45: 2721-33. [CrossRef] [PubMed]

Buac, Milijana, and Margarita Kaushanskaya. 2020. Predictors of Theory of Mind performance in bilingual and monolingual children. International Journal of Bilingualism 24: 339-59. [CrossRef]

Bull, Rebecca, Lousie H. Phillips, and Claire A. Conway. 2008. The role of control functions in mentalizing: Dual-task studies of theory of mind and executive function. Cognition 107: 663-72. [CrossRef]

Burnel, Morgane, Marcela Perrone-Bertolotti, Anne Reboul, Monica Baciu, and Stephanie Durrleman. 2018. Reducing the language content in ToM tests: A developmental scale. Developmental Psychology 54: 293-307. [CrossRef]

Carlson, Stephanie M., and Andrew N. Meltzoff. 2008. Bilingual experience and executive functioning in young children. Developmental Science 11: 282-98. [CrossRef]

Cheung, Charlton, Siew Chua, Vinci Cheung, Liu Khong, Kelly Tai, Takara Wong, Takara Ho, and Grainne McAlonan. 2009. White matter fractional anisotrophy differences and correlates of diagnostic symptoms in autism. Journal of Child Psychology and Psychiatry 50: 1102-12. [CrossRef]

Çokal, Derya, Gabriel Sevilla, William S. Jones, Vitor Zimmerer, Felicity Deamer, Maggie Douglas, Helen Spencer, Douglas Turkington, Nicol Ferrier, Rosemary Varley, and et al. 2018. The language profile of formal thought disorder. Schizophrenia 4: 1-8. [CrossRef]

de Villiers, Jill G. 1998. On acquiring the structural representations for false complements. New Perspectives on Language Acquisition, University of Massachusetts Occasional Papers in Linguistics 22: 125-36.

de Villiers, Jill G. 2000. Language and theory of mind: What are the developmental relationships? In Understanding Other Minds: Perspectives from Developmental Cognitive Neuroscience. Edited by Simon Baron-Cohen, Helen Tager-Flusberg and David Cohen. Oxford: Oxford University Press, pp. 83-123.

de Villiers, Jill G. 2005. Can language acquisition give children a point of view? In Why Language Matters for Theory of Mind. Oxford: Oxford University Press.

de Villiers, Jill G. 2007. The interface of language and theory of mind. Lingua 117: 1858-78. [CrossRef] [PubMed] de Villiers, Jill G., and Peter A. de Villiers. 2000. Linguistic determinism and the understanding of false beliefs. Children's Reasoning and the Mind 189: 226.

Derksen, Daniel G., Michelle C. Hunsche, Megan E. Giroux, Deborah A. Connolly, and Daniel M. Bernstein. 2018. A systematic review of theory of mind's precursors and functions. Zeitschrift Psychol 226: 87-97. [CrossRef]

Devine, Rory T., and Claire Hughes. 2013. Silent films and strange stories: Theory of mind, gender, and social experiences in middle childhood. Child Development 84: 989-1003. [CrossRef] [PubMed]

Diessel, Holger. 2001. The Ordering Distribution of Main and Adverbial Clauses: A Typological Study. Language 77: 433-55. [CrossRef]

Durrleman, Stephanie. 2020. Mentalizing: What's language got to do with it? Language Acquisition 27: $255-75$. [CrossRef] 
Durrleman, Stephanie, and Julie Franck. 2015. Exploring links between language and cognition in autism spectrum disorders: Complement sentences, false belief, and executive functioning. Journal of Communication Disorders 54: 15-31. [CrossRef]

Durrleman, Stephanie, Morgane Burnel, Evelyne Thommen, Nadège Foudon, Sandrine Sonié, Anne Reboul, and Pierre Fourneret. 2016. The language cognition interface in ASD: Complement sentences and false belief reasoning. Research in Autism Spectrum Disorders 21: 109-20. [CrossRef]

Durrleman, Stephanie, Morgane Burnel, Jill G. De Villiers, Evelyne Thommen, Rachel Yan, and Hélène Delage. 2019. The impact of grammar on mentalizing: A training study including children with autism spectrum disorder and developmental language disorder. Frontiers in Psychology 10: 2478. [CrossRef]

Ebert, Kerry D., Diane Rak, Caitlyn M. Slawny, and Louis Fogg. 2019. Attention in bilingual children with developmental language disorder. Journal of Speech, Language, and Hearing Research 62: 979-92. [CrossRef]

Fisher, Naomi, Francesca Happé, and Judy Dunn. 2005. The relationship between vocabulary, grammar, and false belief task performance in children with autistic spectrum disorders and children with moderate learning difficulties. Journal of Child Psychology and Psychiatry 46: 409-19. [CrossRef] [PubMed]

Fleckstein, Alice, Philippe Prévost, Laurice Tuller, Eva Sizaret, and Rasha Zebib. 2018. How to identify SLI in bilingual children: A study on sentence repetition in French. Language Acquisition 25: 85-101. [CrossRef]

Forgeot, d'Arc Baudouin, and Franck Ramus. 2011. Belief attribution despite verbal interference. Quarterly Journal of Experimental Psychology 64: 975-90. [CrossRef] [PubMed]

Friedman, Naomi P., and Akira Miyake. 2004. The relations among inhibition and interference control functions: A latent-variable analysis. Journal of Experimental Psychology General 133: 101-35. [CrossRef] [PubMed]

Frith, Uta. 2003. Autism: Explaining the Enigma. Oxford: Blackwell Publishing.

Frith, Uta, and Francesca Happé. 1999. Theory of mind and self-consciousness: What is it like to be autistic? Mind E Language 14: 82-89.

Gardiner, Emily, and Grace Iarocci. 2018. Everyday executive function predicts adaptive and internalizing behavior among children with and without autism spectrum disorder. Autism Research 11: 284-95. [CrossRef]

Georgas, Dimitrios, Ioannis Paraskevopoulos, Elias Besevegis, Nikolaos Giannitsas, and Konstantine Mylonas.

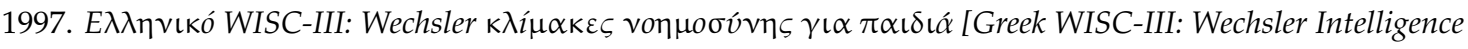
Scale for Children]. Athens: Ellinika Grammata.

Goetz, Peggy. 2003. The effects of bilingualism on theory of mind development. Bilingualism: Language and Cognition 6: 1-15. [CrossRef]

Gonzalez-Barrero, Ana Maria, and Aparna Nadig. 2018. Bilingual children with autism spectrum disorders: The impact of amount of language exposure on vocabulary and morphological skills at school age. Autism Research 11: 1667-78. [CrossRef]

Gonzalez-Barrero, Ana Maria, and Aparna Nadig. 2019. Can bilingualism mitigate set-shifting difficulties in children with Autism Spectrum Disorders? Child Development 90: 1043-60. [CrossRef]

Haegeman, Liliane. 2006. Conditionals, factives and the left periphery. Lingua 116: 1651-69. [CrossRef]

Hambly, Catherine, and Eric Fombonne. 2012. The Impact of Bilingual Environments on Language Development in Children with Autism Spectrum Disorders. Journal of Autism and Developmental Disorders 42: 1342-52. [CrossRef] [PubMed]

Hampton, Sarah, Hugh Rabagliati, Antonella Sorace, and Sue Fletcher-Watson. 2017. Autism and bilingualism: A qualitative interview study of parents' perspectives and experiences. Journal of Speech, Language, and Hearing Research 60: 435-46. [CrossRef]

Happé, Francesca G. E. 1994. Wechsler IQ profile and theory of mind in autism: A research note. Journal of Child Psychology and Psychiatry 35: 1461-71. [CrossRef]

Happé, Francesca G. E. 1995. The role of age and verbal ability in the theory of mind task performance of subjects with autism. Child Development 66: 843-55. [CrossRef] [PubMed]

Hasher, Lynn, Christie Chung, Cynthia P. May, and Natalie Foong. 2002. Age, time of testing, and proactive interference. Canadian Journal of Experimental Psychology 56: 200-7. [CrossRef]

Hinzen, Wolfram, and Joana Rosselló. 2015. The linguistics of schizophrenia: Thought disturbance as language pathology across positive symptoms. Frontiers in Psychology 6: 971. [CrossRef] [PubMed]

Hinzen, Wolfram, and Michelle Sheehan. 2013. The Philosophy of Universal Grammar. Oxford: OUP Oxford.

Hoff, Erika, Cynthia Core, Silvia Place, Rosario Rumiche, Melissa Señor, and Marisol Parra. 2012. Dual language exposure and early 332 bilingual development. Journal of Child Language 39: 1-27. [CrossRef] 
Jones, Catherine R. G., Emily Simonoff, Gillian Baird, Andrew Pickles, Anita J. S. Marsden, Jenifer Tregay, Francesca Happé, and Tony Charman. 2018. The association between theory of mind, executive function, and the symptoms of autism spectrum disorder. Autism Research 11: 95-109. [CrossRef]

Joseph, Robert M., and Helen Tager-Flusberg. 2004. The relationship of theory of mind and executive functions to symptom type and severity in children with autism. Development and Psychopathology 16: 137. [CrossRef]

Klem, Marianne, Monica Melby-Lervåg, Bente Hagtvet, Solveig-Alma H. Lyster, Jan-Eric Gustafsson, and C. Hulme. 2015. Sentence repetition is a measure of children's language skills rather than working memory limitations. Developmental Science 18: 146-54. [CrossRef]

Kouklari, Evangelia C., Stella Tsermentseli, and Bonnie Auyeung. 2018. Executive function predicts theory of mind but not social verbal communication in school-aged children with autism spectrum disorder. Research in Developmental Disabilities 76: 12-24. [CrossRef] [PubMed]

Leung, Rachel C., Vanessa M. Vogan, Tamara L. Powell, Evdokia Anagnostou, and Margot J. Taylor. 2016. The role of executive functions in social impairment in Autism Spectrum Disorder. Child Neuropsychology 22: 336-44. [CrossRef]

Li, Honglan, and Man-Tak Leung. 2020. Relations between verb factivity and first-order and second-order false belief understanding: Evidence from Mandarin-speaking typically developing children and children with autism spectrum disorders. Clinical Linguistics \& Phonetics 34: 185-200.

Lust, Barbara, Claire Foley, and Cristina Dye. 2015. The first language acquisition of complex sentences. In The Cambridge Handbook of Child Language (Cambridge Handbooks in Language and Linguistics). Edited by Edith Bavin and Letitia Naigles. Cambridge: Cambridge University Press, pp. 298-323.

Marinis, Theodoros, and Sharon Armon-Lotem. 2015. Sentence repetition. In Assessing Multilingual Children: Disentangling Bilingualism from Language Impairment. Bristol: Multilingual Matters, pp. 95-124.

Mazza, Monica, Melania Mariano, Sara Peretti, Francesco Masedu, Maria Chiara Pino, and Marco Valenti. 2017. The role of theory of mind on social information processing in children with autism spectrum disorders: A mediation analysis. Journal of Autism and Developmental Disorders 47: 1369-79. [CrossRef] [PubMed]

Meir, Natalia, Joel Walters, and Sharon Armon-Lotem. 2016. Disentangling SLI and bilingualism using sentence repetition tasks: The impact of L1 and L2 properties. International Journal of Bilingualism 20: 421-52. [CrossRef]

Meir, Natalia, and Rama Novogrodsky. 2019. Prerequisites of third-person pronoun use in monolingual and bilingual children with autism and typical language development. Frontiers in Psychology 10: 2289. [CrossRef]

Meir, Natalia, and Rama Novogrodsky. 2020. Syntactic abilities and verbal memory in monolingual and bilingual children with High Functioning Autism (HFA). First Language 40: 341-66. [CrossRef]

Morris, Neil, and Dylan Jones. 1990. Memory updating in working memory: The role of the central executive. British Journal of Psychology 81: 111-21. [CrossRef]

Nguyen, Thien-Kim, and Janet W. Astington. 2014. Reassessing the bilingual advantage in theory of mind and its cognitive underpinnings. Bilingualism: Language and Cognition 17: 396-409. [CrossRef]

O'Hearn, Kristen, Miya Asato, Sarah Ordaz, and Beatriz Luna. 2008. Neurodevelopment and executive function in autism. Development and Psychopathology 20: 1103-32. [CrossRef]

Ohashi, Kaori, PatMirenda, Stefka Marinova-Todd, Catherine Hambly, Eric Fombonne, Peter Szatmari, Susan Bryson, Wendy Roberts, Isabel Smith, Tracy Vaillancourt, and et al. 2012. Comparing early language development in monolingual- and bilingual-exposed young children with autism spectrum disorders. Research in Autism Spectrum Disorders 6: 890-97. [CrossRef]

Ozonoff, S., B. F. Pennington, and S. J. Rogers. 1991. Executive function deficits in high-functioning autistic individuals: Relationship to theory of mind. Journal of Child Psychology and Psychiatry 32: 1081-105. [CrossRef]

Paradis, Johanne. 2010. The interface between bilingual development and specific language impairment. Applied Psycholinguistics 31: 227. [CrossRef]

Pearson, Barbara Z., Sylvia C. Fernández, and D. Kimbrough Oller. 1993. Lexical development in bilingual infants and toddlers: 347 Comparison to monolingual norms. Language Learning 43: 93-120. [CrossRef]

Peña, Elizabeth D., Lisa M. Bedore, Prarthana Shivabasappa, and Luping Niu. 2018. Effects of divided input on bilingual children with language impairment. International Journal of Bilingualism 24: 62-78. [CrossRef]

Pennington, Bruce F., Sally J. Rogers, Loisa Bennetto, Elizabeth M. Griffith, D. Taffy Reed, and Vivian Shyu. 1997. Validity tests of the executive dysfunction hypothesis of autism. In The Autism as an Executive Disorder. Edited by J. Russell. Oxford: Oxford University Press, pp. 143-78. 
Peristeri, Eleni, Maria Andreou, and Ianthi M. Tsimpli. 2017. Syntactic and story structure complexity in the narratives of high-and low-language ability children with autism Spectrum disorder. Frontiers in Psychology 8: 2027. [CrossRef] [PubMed]

Peristeri, Eleni, Eleni Baldimtsi, Maria Andreou, and Ianthi M. Tsimpli. 2020. The impact of bilingualism on the narrative ability and the executive functions of children with autism spectrum disorders. Journal of Communication Disorders 85: 105999. [CrossRef] [PubMed]

Perner, Josef, Uta Frith, Alan M. Leslie, and Suzan R. Leekam. 1989. Exploration of the autistic child's theory of mind: Knowledge, belief, and communication. Child Development 60: 689-700. [CrossRef]

Petersen, Jill M., Stefka H. Marinova-Todd, and Pat Mirenda. 2012. Brief report: An exploratory study of lexical skills in bilingual children with autism spectrum disorder. Journal of Autism and Developmental Disorders 42: 1499-503. [CrossRef]

Polišenská, Kamila, Shula Chiat, and Penny Roy. 2015. Sentence repetition: What does it measure? International Journal of Language and Communication Disorders 50: 106-18. [CrossRef]

Radford, Andrew. 1997. Syntactic Theory and the Structure of English: A Minimalist Approach. Cambridge: Cambridge University Press.

Roussou, Anna, and Anastasios Tsangalidis. 2010. Reconsidering the 'Modal Particles' in Modern Greek. Journal of Greek Linguistics 10: 45-73.

Russell, James E. 1997. Autism as an Executive Disorder. Oxford: Oxford University Press.

Russell, James, Rebecca Saltmarsh, and Elisabeth Hill. 1999. What do executive factors contribute to the failure on false belief tasks by children with autism? Journal of Child Psychology and Psychiatry 40: 859-68. [CrossRef] [PubMed]

Rutter, Michael, Ann Le Couteur, and Catherine Lord. 2003. ADI-R: The Autism Diagnostic Interview-Revised. Los Angeles: Western Psychological Services.

Schick, Brenda, Peter de Villiers, Jill de Villiers, and Roberts Hoffmeister. 2007. Language and theory of mind: A study of deaf children. Child Development 78: 376-96. [CrossRef]

Schneider, Walter, Amy Eschman, and Anthony Zuccolotto. 2012. E-Prime User's Guide. Pittsburgh: Psychology Software Tools, Inc.

Schuh, Jillian M., and Inge-Marie Eigsti. 2012. Working memory, language skills, and autism symptomatology. Behavioral Sciences 2: 207-18. [CrossRef] [PubMed]

Semel, Eleanor, Elisabeth H. Wiig, and Wayne A. Secord. 2003. Clinical Evaluation of Language Fundamentals, (CELF-4). San Antonio: The Psychological Corporation.

Semrud-Clikeman, Margaret, Jenifer Walkowiak, Alison Wilkinson, and Brianne Butcher. 2010. Executive Functioning in Children with Asperger Syndrome, ADHD-Combined Type, ADHD-Predominately Inattentive Type, and Controls. Journal of Autism and Developmental Disorders 40: 1017-27. [CrossRef] [PubMed]

Sinzig, Judith, Dagmar Morsch, Nicole Bruning, Martin H. Schmidt, and Gerd Lehmkuhl. 2008. Inhibition, flexibility, working memory and planning in autism spectrum disorders with and without comorbid ADHD-symptoms. Child and Adolescent Psychiatry and Mental Health 2: 4. [CrossRef]

Smith, Edward E., and John Jonides. 1999. Storage and executive processes in the frontal lobes. Science 283: 1657-61. [CrossRef]

Solomon, Marjorie, Sally J. Ozonoff, Stefan Ursu, Suzan Ravizza, Neil Cummings, Stanford Ly, and Cameron S. Carter. 2009. The neural substrates of cognitive control deficits in autism spectrum disorders. Neuropsychologia 47: 2515-26. [CrossRef]

Tager-Flusberg, H. 2013. The Relationship Between and Social Cognition: Lessons from Autism. Other Children, Other Languages: Issues in the Theory of Language Acquisition 359.

Thompson, Sandra A., Robert E. Longacre, and Shin Ja J. Hwang. 1985. Adverbial clauses. Language Typology and Syntactic Description 2: 171-234.

Tomasello, Michael. 2003. Constructing a Language: A Usage-Based Theory of Language Acquisition. Cambridge: Harvard University Press.

Torske, Tonje, Terje Nærland, Merete G. Øie, Nina Stenberg, and Ole A. Andreassen. 2018. Metacognitive aspects of executive function are highly associated with social functioning on parent-rated measures in children with autism spectrum disorder. Frontiers in Behavioral Neuroscience 11: 258. [CrossRef]

Unsworth, Sharon. 2013. UBILEC: Utrecht Bilingual language Exposure Calculator. Unpublished manuscript. 
Valicenti-McDermott, Maria, Nancy Tarshis, Melissa Schouls, Molly Galdston, Kathryn Hottinger, Rosa Seijo, L. Shulman, and Shlomo Shinnar. 2013. Language differences between monolingual English and bilingual English-Spanish young children with autism spectrum disorders. Journal of Child Neurology 28: 945-48. [CrossRef]

Varley, Rosemary, and Michael Siegal. 2000. Evidence for cognition without grammar from causal reasoning and 'theory of mind'in an agrammatic aphasic patient. Current Biology 10: 723-26. [CrossRef]

Vieu, L., M. Bras, N. Asher, and M. Aurnague. 2005. Locating adverbials in discourse. Journal of French Language Studies, Cambridge University Press (CUP) 15: 173-93. [CrossRef]

Vogindroukas, Ioannis, Athanasios Protopapas, and Georgios Sideridis. 2009. Experiment on the Expressive Vocabulary (Greek Version of Renfrew Word Finding Vocabulary Test). Chania: Glafki.

White, Susan W., Thomas Ollendick, Anne Marie Albano, Donald Oswald, Cynthia Johnson, Michael A. SouthamGerow, Inyoung Kim, and Lawrence Scahill. 2013. Randomized controlled trial: Multimodal anxiety and social skill intervention for adolescents with autism spectrum disorder. Journal of Autism and Developmental Disorders 43: 382-94. [CrossRef]

Williams, David. 2010. Theory of own mind in autism: Evidence of a specific deficit in self-awareness? Autism 14: 474-94. [CrossRef]

Williams, Diane L., Gerald Goldstein, Patricia A. Carpenter, and Nancy J. Minshew. 2005. Verbal and spatial working memory in autism. Journal of Autism and Developmental Disorders 35: 747. [CrossRef]

Publisher's Note: MDPI stays neutral with regard to jurisdictional claims in published maps and institutional affiliations.

(C) 2020 by the authors. Licensee MDPI, Basel, Switzerland. This article is an open access article distributed under the terms and conditions of the Creative Commons Attribution (CC BY) license (http://creativecommons.org/licenses/by/4.0/). 